This document is the accepted manuscript version of the following article:

Heringa, M. F., Slowik, J. G., Goldmann, M., Signore11, R., Hemberger, P., \& Bodi, A. (2017). The distant double bond determines the fate of the carboxylic group in the dissociative photoionization of oleic acid. Chemphyschem, 18(24), 3595-3604. https://doi.org/10.1002/cphc. 201700983

\title{
The Distant Double Bond Determines the Fate of the Carboxylic Group in the Dissociative Photoionization of Oleic Acid
}

\author{
Maarten F. Heringa, ${ }^{1,3}$ Jay G. Slowik, ${ }^{1}$ Maximilian Goldmann, ${ }^{2}$ Ruth Signorell, ${ }^{2}$ Patrick \\ Hemberger, ${ }^{3}$ and Andras Bodi ${ }^{3, *}$ \\ ${ }^{1}$ Laboratory of Atmospheric Chemistry, Paul Scherrer Institute, 5232 Villigen PSI, Switzerland \\ ${ }^{2}$ Department of Chemistry and Applied Biosciences, Laboratory of Physical Chemistry, ETH \\ Zürich, Vladimir-Prelog-Weg 2, 8093 Zürich, Switzerland \\ ${ }^{3}$ Laboratory for Synchrotron Radiation and Femtochemistry, Paul Scherrer Institute, 5232 \\ Villigen PSI, Switzerland
}

\begin{abstract}
The valence threshold photoionization of oleic acid has been studied using synchrotron VUV radiation and imaging photoelectron photoion coincidence (iPEPICO) spectroscopy. An oleic acid aerosol beam was impacted on a copper thermodesorber, heated to $130{ }^{\circ} \mathrm{C}$, to evaporate the particles quantitatively. Upon threshold photoionization, oleic acid produces the intact parent ion first, followed by dehydration at higher energies. Starting at ca. $10 \mathrm{eV}$, a large number of fragment ions slowly rise suggesting several fragmentation coordinates with quasi-degenerate activation energies. However, water loss is the dominant low-energy dissociation channel, and it is shown to be closely related to the unsaturated carbon chain. In the lowest-barrier process, one of the four allylic hydrogen atoms is transferred to the carboxyl group to form the leaving water molecule and a cyclic ketone fragment ion. A statistical model to analyze the breakdown diagram and measured rate constants yields a $0 \mathrm{~K}$ appearance energy of $9.77 \mathrm{eV}$, which can be compared with the density functional theory result of $9.19 \mathrm{eV}$. Alternative H-transfer steps yielding a terminal $\mathrm{C}=\mathrm{O}$ group are ruled out based on energetics and kinetics arguments. Some of the previous photoionization mass spectrometric studies also reported 2 amu and 26 amu loss fragment ions, corresponding to hydrogen and acetylene loss. We could not identify such peaks in the mass spectrum of oleic acid.
\end{abstract}

*E-mail address: andras.boedi@psi.ch, tel.: +41 563104471. 
Keywords: aerosol; photoelectron photoion coincidence spectroscopy; vacuum ultraviolet synchrotron radiation; mass spectrometry; reaction mechanism

\section{Table of Contents entry:}

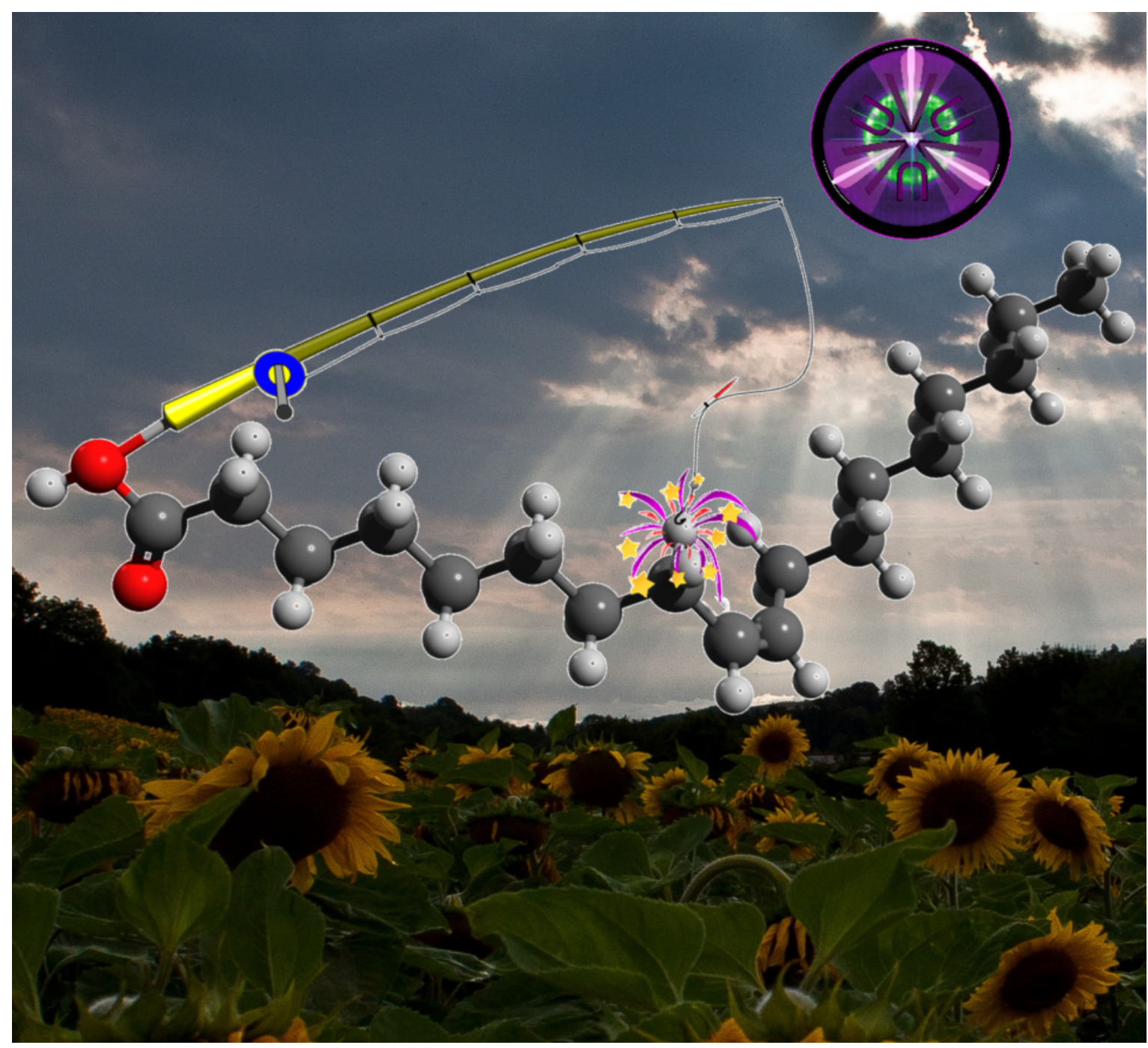

The lowest-energy fragmentation pathway of the oleic acid cation is shown to be water loss by the study of internal energy selected parent ions, instead of McLafferty rearrangement usually found in carboxylic acids. Calculations reveal that the positive charge is partially delocalized to the double bond, and the remote allylic hydrogens may transfer to the $\mathrm{OH}$ group to form the leaving water molecule more easily, which then yields a cyclic ketone fragment ion. 


\section{$1 \quad$ Introduction}

The identification of organics in the atmosphere, estimated to represent a diversity of $10^{4}-10^{5}$ compounds, is an ongoing effort. ${ }^{[1]}$ In particular, atmospheric aerosols have a great influence on human well-being: exposure to high aerosol concentrations, e.g., during smog events, can lead to adverse health effects directly. ${ }^{[2]}$ Long-term exposure to moderate aerosol concentrations has been associated with increased mortality and was found to increase the risk of cardiopulmonary disease and lung cancer. ${ }^{[3]}$

Organic aerosol (OA) is an important fraction of the ambient fine aerosol. ${ }^{[4,5]}$ However, due to its complexity, characterization and source apportionment of the primary and secondary organic aerosol (POA/SOA) remains difficult. ${ }^{[6]}$ The importance of cooking emissions has been recognized decades ago using organic marker compounds in conjunction with a chemical mass balance model. ${ }^{[7,8]}$ More recently, organic aerosol cooking emissions were measured in major European cities, such as London, ${ }^{[9]}$ Barcelona, ${ }^{[10]}$ and Paris ${ }^{[11]}$ by online aerosol mass spectrometry (AMS), which has become an established technique for time-resolved analysis of the concentration and composition of ambient aerosol ${ }^{[12]}$ and the source apportionment of its organic fraction. ${ }^{[1],[13]}$ To ensure quantitative detection of most atmospherically relevant organic and inorganic species excluding black carbon and mineral dust, the instrument utilizes vaporization at about $600{ }^{\circ} \mathrm{C}$ followed by electron ionization (EI) at $70 \mathrm{eV}$. The high vaporization temperature and hard ionization induce significant thermal decomposition and ionic fragmentation processes in the mass spectrum, making the molecular assignment of environmentally relevant mixtures tenuous. Although organic compounds, saturated and unsaturated hydrocarbons, are known to react with a variety of atmospheric oxidants, such as $\mathrm{OH}$ radicals and ozone, molecular markers and statistical models have been shown to be useful tools to identify aerosol sources and contributions. ${ }^{[14-16]}$

Soft photoionization using vacuum ultraviolet radiation, either produced by a VUV lamp, ${ }^{[17]}$ or using monochromatic $10.5 \mathrm{eV}$ obtained by frequency tripling the third harmonic of a $\mathrm{Nd}: Y A G$ laser ${ }^{[18]}$ can both be used to suppress ionic fragmentation processes and to simplify the mass spectrum. Component speciation can be further facilitated by recording the mass spectrum of known and typical aerosol constituents. ${ }^{[19]}$ 
Dissociative ionization processes leading to spectral complexity can be greatly reduced by using soft and tunable VUV photoionization. ${ }^{[20-22]}$ A recent synchrotron-based VUV photoionization smog chamber study has demonstrated the possibility to monitor changes in the gas and particle phase composition simultaneously. ${ }^{[23]}$ However, photoionization mass spectra of complex ambient aerosols will always be an assembly of ions and fragments from thousands of compounds. In a previous work, ${ }^{[24]}$ we discussed how investigating the valence threshold photoionization of salient aerosol components, for instance adipic acid, an $\alpha, \omega$-dicarboxylic acid, by photoelectron photoion coincidence spectroscopy ${ }^{[25]}$ can contribute to our understanding of the fragmentation driving forces and patterns of different compound classes.

Oleic acid (cis-9-octadecenoic acid, $\mathrm{C}_{18} \mathrm{H}_{34} \mathrm{O}_{2}$ ) is an abundant $\mathrm{C}_{18}$ monounsaturated monocarboxylic acid, which, similar to linoleic and palmitic acid, is a major component of particulate cooking emissions. ${ }^{[26]}$ Although laboratory studies on pure oleic acid suggested an atmospheric lifetime in the range of seconds, ${ }^{[27]}$ atmospheric measurements indicated a lifetime on the order of hours to days, ${ }^{[28,29]}$ which makes oleic acid a suitable tracer for cooking emissions. ${ }^{[8]}$ The photoelectron spectrum of oleic acid was first recorded by Katsumata along with that of stearic acid and polyunsaturated fatty acids in $2004 \cdot{ }^{[30]} \mathrm{He}$ evaporated the bulk sample using IR heating, and reported an adiabatic ionization energy of $8.63 \mathrm{eV}$ and vertical transitions corresponding to ionization from $\pi$ - and $\sigma$-type orbitals involving the $\mathrm{C}=\mathrm{C}$ double bond. He also found that the ionization energy decreases monotonically with increasing unsaturation. Also in 2004, Nash et al. prepared a collimated beam of oleic acid aerosol particles, vaporized them using a $\mathrm{CO}_{2}$ laser or a thermodesorber, and ionized the isolated molecules using 8.75 or $10.48 \mathrm{eV}$ laser radiation. ${ }^{[31]}$ A year later, Mysak et al. employed tunable and quasicontinuous synchrotron radiation in a similar thermodesorber setup to study the photoionization mass spectrometry of oleic, linoleic, and linolenic acid, together with cholesterol. ${ }^{[21]}$ The parent ion and the water-loss fragment ion at $m / z=282$ and 264 have been observed both times, and a quite significant acetylene-loss peak was also reported at $m / z=256$ in the synchrotron-based work. A further fragment ion, $\mathrm{H}_{2}$-loss at $\mathrm{m} / \mathrm{z}=280$ was reported in later soft photoionization aerosol mass spectra of oleic acid. ${ }^{[17,19]}$ Fang et al. also used synchrotron VUV radiation to study the mass spectrum of oleic acid by vaporizing oleic acid aerosols using a copper thermodesorber, and reported both acetylene loss and $\mathrm{H}_{2}$ loss fragment ions in the mass spectrum at already 9.5 and $9.0 \mathrm{eV}$ photon energies, respectively. ${ }^{[32]}$ This is in some contrast with the results of Hanna et 
al., ${ }^{[33]}$ who comprehensively characterized IR-VUV-ITMS experiments and found that only the parent and water loss peaks stand out, and a panoply of lighter fragments arises when increasing the overall energy available to the system. Although it does not show an acetylene-loss peak at $m / z=256$, the electron ionization mass spectrum ${ }^{[34]}$ also exhibits a weak $\mathrm{H}_{2}$-loss peak at $m / \mathrm{z}=$ 280. This has motivated us to try and establish the soft ionization fragmentation mechanism of oleic acid definitively.

Furthermore, recent studies on medium-sized organics have shown that internal energy selection in threshold photoionization is a powerful tool to determine complicated fragmentation mechanisms unambiguously when combined with ab initio calculations. ${ }^{[24,35]}$ The breakdown diagram and TOF distributions give clues to the barrier heights and can be used to distinguish parallel and sequential processes, as well. Combined with reaction path calculations that yield consistent energetics, complex dissociation reaction paths can, thus, be readily unveiled. Our objective has also been to determine whether such an approach can be extended to large organic molecules, such as oleic acid. The main difficulty with calculations in general, and potential energy surface exploration in particular, lies with the exponentially expanding conformational space and the $N^{4}-N^{6}$ scaling of quantum chemical calculations with increasing molecular size. Therefore, we can only explore a tiny subspace of the conformational space of the system at an inferior level of theory compared with smaller molecules. However, as will be shown for the case of water loss from the oleic acid parent ion, such an approach, although relying on density functional theory (DFT) calculations instead of composite methods for the stationary points along the reaction coordinate, may still yield valuable insights for floppy systems consisting of ca. 20 heavy atoms.

\section{Experimental and computational methods}

Oleic acid was obtained from Sigma-Aldrich (purity 99.6\%) and used as received. Vacuum ultraviolet (VUV) photoionization experiments were performed using the Imaging Photoelectron Photoion Coincidence (iPEPICO) endstation at the VUV beamline of the Swiss Light Source. A comprehensive description of the beamline can be found elsewhere ${ }^{[36]}$ and is only briefly reviewed here. Synchrotron radiation from a bending magnet, dispersed by a grazing incidence monochromator using a 600 lines $/ \mathrm{mm}$ laminar grating, is focused into a differentially 
pumped gas filter, operated with a mixture of $\mathrm{Ar}, \mathrm{Kr}$, and $\mathrm{Ne}$ in the 7-14 eV energy range to suppress higher-order radiation. The high harmonic free, monochromatic VUV radiation then enters the ionization chamber of the iPEPICO endstation and ionizes the sample in a $4 \times 2 \mathrm{~mm}^{2}$ interaction region.

\subsection{Aerosol sampling setup}

Several dedicated sample delivery systems have been designed to bring non-volatile compounds into the gas phase to study their molecular properties. Aside from (matrix-assisted) laser desorption, ${ }^{[37,38]}$ samples can be evaporated in a heated oven in a buffer gas, and expanded into vacuum to create a cold molecular beam of the isolated species as well as clusters thereof, ${ }^{[39-}$ ${ }^{41]}$ and to study the unimolecular decomposition mechanism of the sample by pyrolysis. ${ }^{[42]}$ Such a molecular beam source requires that the vapor pressure of the sample is on the order of $1 \mathrm{mbar}$ before thermal decomposition sets in. Much lower vapor pressures are sufficient if the sample is evaporated directly into the ionization chamber, ${ }^{[43]}$ but the mildest approach to bringing nonvolatile compounds in the isolated phase thermally has been shown to lead through the aerosol phase: when a collimated beam of sample nanoparticles impinges on the surface of a thermodesorber, similar to, but operated at much lower temperatures than the one used in conventional EI-AMS, non-volatile and labile samples, such as hypergolic ionic liquids, ${ }^{[44]}$ biomolecules, ${ }^{[45]}$ among them vitamins ${ }^{[46]}$ and oligopeptides ${ }^{[47]}$ can be brought in the gas phase intact. Similar to the previous synchrotron-based work on oleic acid by Mysak et al., ${ }^{[21]}$ we constructed a continuous aerosol vaporization source, which consists of three main components, i.e., aerosol generation, aerosol inlet and aerosol evaporation.

Oleic acid aerosol was generated by nebulization of the pure sample using nitrogen gas. An overflow outlet at the nebulizer was used to keep the inlet system at ambient pressure. The aerosol was sampled through an aerodynamic lens with a $200 \mu \mathrm{m}$ critical orifice at a flow rate of approximately $6 \mathrm{~cm}^{3} \mathrm{~s}^{-1} \cdot{ }^{[48-52]}$ The aerodynamic lens focuses particles in the $20-400 \mathrm{~nm}$ size range into a collimated particle beam perpendicular to the VUV radiation axis and directs them at the heated conical copper tip of the in-house built thermodesorber, shown in Figure 1. The position of the temperature controlled heated finger with $3 \mathrm{~mm}$ diameter and a concave, conically shaped tip is adjustable in all three directions using micrometer screws and was 
optimized for ion signal intensity. Upon impact, the heating effect of the finger is slightly enhanced by the kinetic energy of the aerosol particles to evaporate the particles in high vacuum, creating a gas phase plume in the immediate vicinity of the ionization region. As reported by Mysak et al., ${ }^{[21]}$ the oleic acid signal reaches its maximum at comparably low tip temperatures, and we ran the experiments at $130^{\circ} \mathrm{C}$. The vaporizer is electrically isolated, and can be floated at a potential to minimize its impact on the extraction field in the ionization region. In fact, in the photoelectron velocity map imaging (VMI) experiments reported here, we could ground the thermodesorber and move it to within $2 \mathrm{~mm}$ of the synchrotron beam without emitting surface electrons or significantly affecting photoelectron VMI conditions. The hot finger was heated by a heating coil (not shown in Figure 1) in the experiments herein. Later, we adapted the finger to host a reduced type $\mathrm{K}$ thermocouple with a resistance of ca. 3-4 $\Omega$, to which a low voltage of less than $5 \mathrm{~V}$ is applied to heat the thermodesorber to temperatures below $350{ }^{\circ} \mathrm{C}$. Although the small resistance of the heating element yields currents up to $1 \mathrm{~A}$ close to the ionization region and within the magnetically shielded volume of the spectrometer, the induced magnetic field never affected the electron extraction noticeably. Our setup images threshold electrons onto a smaller than $1 \mathrm{~mm}$ spot in the center of the detector, which corresponds to a resolution of 2-3 $\mathrm{meV}$. With the thermodesorber in operation, the spot size increased to $1.5 \mathrm{~mm}$, corresponding to a resolution of ca. $5 \mathrm{meV}$. The thermodesorber had no observable effect on the time-of-flight mass spectra.

\section{2 iPEPICO spectrometer}

The monochromatic VUV beam crosses the evaporated sample plume in the interaction region, see Figure 1(b), and a constant, $120 \mathrm{~V} \mathrm{~cm}^{-1}$, electric field accelerates the resulting photoelectrons and photoions in opposite directions. The electrons are velocity map imaged onto a DLD40 Roentdek position-sensitive delay-line detector. As their time-of-flight (TOF) is negligible, electrons also act as start signal for the ion TOF analysis. The cations are accelerated downward in a linear TOF mass spectrometer and space focused on a microchannel plate detector. High ion residence times in the relatively long and low $1^{\text {st }}$ acceleration field enable unimolecular dissociation rate constant measurements in the $10^{3}-10^{7} \mathrm{~s}^{-1}$ range: if an ion dissociates in the acceleration region, its TOF will be between that of the parent and the fragment 
ion, yielding quasi-exponentially decaying TOF peaks characteristic of the dissociation rate constant. ${ }^{[53]}$ Electron arrival times and positions, and ion arrival times are recorded using a triggerless multiple-start/multiple-stop data acquisition scheme. ${ }^{[54]}$

Internal energy selection is achieved by threshold photoionization, in which all excess energy above the adiabatic ionization energy is deposited as internal energy of the parent ion. Thus, the sum of the known neutral thermal energy and this excess energy determines the total internal energy available for dissociation. Threshold ionization mass spectra are obtained by selecting close to zero kinetic energy electrons as start signal for the TOF analysis. These electrons are imaged into a central spot on the detector together with kinetic energy electrons with negligible off-axis momentum. The contribution of the latter, i.e., the hot electron contamination of the central signal, can be subtracted without VMI reconstruction as proposed by Sztáray and Baer, assuming that the hot electron background in the central spot is represented well by the ring signal around it. ${ }^{[55]}$ Threshold photoionization yields internal energy selected parent ions, which, together with the dissociation rate measurements, allows us to measure the rate curve as a function of internal energy. This can be extrapolated to threshold using statistical theory, thereby accounting for kinetic shifts quantitatively. The experimental rate curve and the fractional abundance of the parent and daughter ions in the threshold photoionization mass spectrum as a function of photon energy, plotted in the breakdown diagram, are modeled simultaneously when determining the threshold to dissociative photoionization. The breakdown diagram and the measured rates only depend on the internal energy distribution of the sample, in other words its temperature, and the ion optics parameters, namely acceleration region lengths and field strengths.

The threshold photoelectron spectrum (TPES) can be obtained by plotting the threshold photoelectron signal as a function of the photon energy for a pure compound or by plotting the sum of the parent and fragment ion mass selected threshold photoelectron signal (ms-TPES) for mixtures in the photon energy range, in which the components' $\mathrm{m} / \mathrm{z}$ peaks do not overlap. As opposed to the breakdown diagram, the TPES depends linearly on both the photon flux and the sample number density in the ionization region. Both approaches have shown that the oleic acid threshold ionization signal decayed above $10.2 \mathrm{eV}$, most probably due to creeping misalignment of the aerosol beam with respect to the thermodesorber or a decrease in aerosol production. In the absence of internal calibration points, we can determine the fragmentation mechanism and its 
driving forces, as is our goal herein, but slow drifts in signal intensity of photoelectron and photoion yield curves cannot be accounted for. Therefore, we only plot the TPES up to $10.2 \mathrm{eV}$ in Figure 2.

\subsection{Ab initio calculations}

Threshold photoionization mass spectra confirmed previous results, ${ }^{[33]}$ indicating a stable parent ion, which dissociates first by water loss, and, at only slightly higher energies, forms numerous fragment ions by parallel and sequential dissociation reactions. Understanding the dissociation channels of the moderately large acetic acid anhydride and dimethyl carbonate cations has been shown to be rather challenging recently. ${ }^{[35,56]}$ In the light of this, we focused on understanding the lowest energy fragmentation channel, water loss. Constrained geometry optimizations and Synchronous Transit-Guided Quasi-Newton (STQN) ${ }^{[57]}$ calculations were carried out to identify the potential reaction paths, and locate stationary points, i.e. minima and transition states, on the potential energy surface, assuming that different hydrogen atoms are involved in forming the leaving water molecule. Exploratory geometry optimizations and energy calculations were carried out at the B3LYP/6-31G(d) level of theory, followed by B3LYP/6$311++\mathrm{G}(\mathrm{d}, \mathrm{p}), \omega \mathrm{B} 97 \mathrm{X}-\mathrm{D} / \mathrm{def} 2-\mathrm{TZVP}$, and M06-2X/def2-TZVP optimization and frequency analysis calculations using the Gaussian 09 program. ${ }^{[58]}$ Unless noted otherwise, reported energies are always evaluated at the optimized geometry at the given level of theory and include unscaled zero-point energy corrections.

\subsection{Statistical model}

When the parent ion dissociates quickly in a single fragmentation channel, the fractional parent and daughter ion abundances are determined by the ratio of the internal energy distribution below and above the dissociation barrier, respectively. In threshold photoionization, the thermal energy distribution of the neutral sample and the excess energy above the adiabatic ionization energy determines the internal energy distribution after ionization. Assuming that the thermal energy distribution of the neutral sample is known, the dissociation threshold is the only variable parameter in the model, and is fitted so that the measured breakdown diagram is best 
reproduced. Absolute experimental dissociation rates are measured in the TOF distributions when the rate constant is below $10^{7} \mathrm{~s}^{-1}$. In such cases, the frequencies of the transitional modes in the transition state are also scaled by a single factor to fit the number of states function and reproduce the measured rate curve and account for the kinetic shift and slight broadening of the breakdown diagram. The fitted rate curve is then extrapolated to the threshold, which corresponds to the $0 \mathrm{~K}$ appearance energy when referenced to the neutral.

As will be shown later, the oleic acid parent ion is metastable when it starts losing a water neutral, indicating that water loss is indeed a slow process at threshold. Thus, the breakdown curves and experimental rate constants have to be modeled in order to account for the kinetic shift, which is the amount of excess energy needed for quantitative water loss on the time scale of the experiment. We constructed a statistical model to the dissociation as described by Sztáray et al. ${ }^{[53]}$ Unimolecular dissociation rates are calculated according to the RRKM approach as $k(E)=\frac{\sigma N^{\ddagger}\left(E-E_{0}\right)}{h \rho(E)}$, where $\sigma$ is the reaction degeneracy and $h$ is Planck’s constant. The density of states of the reactant ion, $\rho(E)$, and the number of states of the transition state, $N^{\ddagger}\left(E-E_{0}\right)$, are obtained based on ab initio harmonic vibrational frequencies and rotational constants. Neglecting tunneling, which may account for an apparent red shift of the appearance energy by about 100 $\mathrm{meV},{ }^{[59]}$ the water-loss dissociation barrier is expected to correspond to the activation energy of $\mathrm{H}$ transfer to the carboxylic $\mathrm{OH}$ group.

\section{$3 \quad$ Results and discussion}

\subsection{Threshold photoelectron spectrum and ionization energy}

The threshold photoelectron spectrum of oleic acid is shown in Figure 2 up to $10.2 \mathrm{eV}$ photon energy. The band maximum of the first band lies at $8.88 \pm 0.05 \mathrm{eV}$, in good agreement with the result of Katsumata of $8.85 \mathrm{eV} \cdot{ }^{[30]}$ We have obtained the photoionization onset as $8.51 \pm$ $0.05 \mathrm{eV}$, which is somewhat lower than Katsumata's value of $8.63 \mathrm{eV}$. The experimental spectra seem to agree in this energy range, but the smaller signal-to-noise ratio may have hidden the lower energy signal in the previous, HeI photoelectron spectrum. Also, in our view, the adiabatic ionization energy cannot be assigned based on photoionization onset unless the Franck-Condon envelope is modeled including the effect of geometry change upon ionization and the analysis of 
the hot bands. In Koopmans' approximation, ionization to the ground cationic state corresponds to the removal of one of the HOMO electrons, which, in the case of oleic acid, is a $\pi$ bonding orbital of the $\mathrm{C}=\mathrm{C}$ double bond, as shown in Figure 3(a). However, the spin density of the cation, also shown in Figure 3(c), suggests a significant HOMO-1 involvement in forming the electron hole upon ionization, delocalizing the charge density and contributing to lowering the ionization energy with increasing unsaturation. ${ }^{[30]}$ The adiabatic ionization energy has been calculated at 8.19, 8.35, and $8.44 \mathrm{eV}$ at the B3LYP/6-311++G(d,p), $\omega B$ 97X-D/def2-TZVP and M06-2X/def2TZVP levels of theory, respectively. In large molecules, even minor conformational change may suppress the nuclear wave function overlap for the $0-0$ transition, and shift the ionization onset to higher energies than the adiabatic ionization potential. These DFT results suggest that the ionization energy could lie slightly below the extrapolated onset of the TPES, but less so than in adipic acid, in which the difference was found to be $1.5 \mathrm{eV} \cdot{ }^{[24]}$ The minimum in the TPES around $9.6 \mathrm{eV}$ reproduces the literature spectrum well, after which the signal continues to rise, in line with the increased density of molecular orbitals. The HOMO and HOMO-1 DFT orbital energies at $-6.68 \mathrm{eV}$ and $-7.92 \mathrm{eV}$ are followed by MOs at energies of $-8.36,-8.63,-8.80,-8.83$ $\mathrm{eV}$ etc., which, when offset to match the ionization energy at around $8.5 \mathrm{eV},{ }^{[60]}$ confirm the large number of electronically excited states above $10 \mathrm{eV}$. Because of sample inlet instabilities, the TPES could not be plotted above $10.2 \mathrm{eV}$ herein.

\subsection{Dissociative photoionization}

The McLafferty rearrangement plays a prominent role in the fragmentation of saturated carboxylic acids. ${ }^{[61]}$ Here, a $\gamma$-hydrogen atom (see Scheme 1) moves to the keto group, followed by $\beta$-cleavage and the formation of the $\mathrm{CH}_{2}=\mathrm{C}(\mathrm{OH})_{2}{ }^{+}$fragment ion at $\mathrm{m} / \mathrm{z}=60$ together with an alkene neutral fragment. Indeed, electron ionization mass spectra, available in the NIST Chemistry Webbook, ${ }^{[34]}$ feature $m / z=60$ as the most prominent peak for hexanoic, heptanoic, and octanoic acid. In longer-chain saturated carboxylic acids, such as palmitic $\left(\mathrm{C}_{16}\right)$ or stearic $\left(\mathrm{C}_{18}\right)$ acid, the $m / z=60$ peak is still the third most intense one with $m / z=43$, a potential fragment of $m / z=60$, being the most intense. In the fragmentation of unsaturated carboxylic acids, the $m / z=60$ peak is only dominant if the leaving neutral fragment is stabilized by conjugation, as in the 5-hexenoic acid cation, which yields butadiene and $\mathrm{CH}_{2}=\mathrm{C}(\mathrm{OH})_{2}{ }^{+}$after $\gamma$ - 
hydrogen transfer. On the other hand, the water-loss peak, which is generally negligible or not at all observed in the spectra of saturated monocarboxylic acids, becomes one of the most intense high- $m / z$ peaks in the unsaturated analogues. In fact, the $18 \mathrm{amu}$ loss peak is the most intense one above $m / z=120$ in the EI mass spectrum of the singly unsaturated oleic acid (9-octadecenoic acid, $\left.\mathrm{C}_{18}\right)$, vaccenic acid (11-octadecenoic acid, $\mathrm{C}_{20}$ ) and even brassidic acid (13-docosenoic acid, $\mathrm{C}_{22}$ ).

As shown in the all-electron mass spectra in Figure 4 and in the breakdown diagram in Figure 5, the first dissociative photoionization channel of oleic acid has indeed been found to be water loss yielding $\mathrm{m} / \mathrm{z}=264$. Interestingly, the degree of fragmentation seen at $11.5 \mathrm{eV}$ in Figure 4 is comparable to the observation of Fang et al. at $10.5 \mathrm{eV},{ }^{[32]}$ which suggests a colder sample vapor in our case, although our thermodesorber temperature was comparable. In adipic acid cations, a $\gamma$ - (or $\beta$-, depending on the reference carboxylic group) hydrogen atom was found to transfer to the carboxylic groups irreversibly and without an overall barrier in the first step of the McLafferty rearrangement, but instead of $\beta$-cleavage afterwards, it eventually moves to a hydroxyl group, forming a leaving water molecule. ${ }^{[24]}$ However, the adipic acid mechanism cannot be carried over to oleic acid because of three reasons: (1) in the absence of a second hydroxyl group, the first step of McLafferty rearrangement could not be followed by the formation of a water leaving group, (2) this mechanism does not depend on whether the carbon chain is unsaturated, and (3) water loss is followed by CO-loss in adipic acid, whereas sequential CO-loss is not observed in oleic acid. Yet, the dominance of water loss at lower energies strongly suggests that it has a unique reaction coordinate, distinct from the manifold of higher energy fragmentation channels, and its identification may also shine light on the role of the $\mathrm{C}=\mathrm{C}$ double bond in water loss. Therefore, we have determined the electronic activation energy to the McLafferty rearrangement to be ca. $1.65 \mathrm{eV}$ above the cation energy by reaction path calculations at the B3LYP/6-31G(d) level of theory, putting the transition state energy at 10.15 $\mathrm{eV}$. This barrier is suggested to arise because of the delocalization of the charge, as seen in the spin density in Figure 3(c). Because only a partial charge is on the carboxyl group, it is less likely to abstract a $\gamma$-hydrogen from the carbon chain.

According to our calculations, $\beta$-hydrogen transfer involves internal conversion, in which the spin density builds up on the transferring $\mathrm{H}$ atom and then jumps over to the $\beta$-carbon. The water loss energy is computed at 10.14, 10.35, $10.39 \mathrm{eV}$ (B3LYP, $\omega$ B97X-D, M06-2X values, 
respectively), and can take place over a conical intersection with a seam at around $2 \mathrm{eV}$ above the ionization energy, i.e., at $10.5 \mathrm{eV}$, based on constrained optimization results. Because similar internal conversion processes are typically fast, ${ }^{[62]}$ we cannot rule out this rearrangement per se. However, the resulting water-loss fragment ion is unstable, because it is composed of a carbon monoxide and a 1,8-heptadecadiene moiety. In fact, sequential CO-loss is exoergic at 9.37, 10.00 , and $10.07 \mathrm{eV}$ (B3LYP, $\omega \mathrm{B} 97 \mathrm{X}-\mathrm{D}, \mathrm{M} 06-2 \mathrm{X}$ values, respectively), suggesting that the $\mathrm{m} / \mathrm{z}$ $=236$ peak should dominate the mass spectrum with the $m / z=264$ peak only observable in a small internal energy window, if at all. In the absence of a dominant $\left(\mathrm{H}_{2} \mathrm{O}+\mathrm{CO}\right)$-loss peak, we can exclude $\beta$-H transfer as a major rearrangement process.

Hydrogen atom transfer from $\mathrm{C} 4-\mathrm{C} 7$ may take place over transition states in the 1.7-2.0 $\mathrm{eV}$ energy range, somewhat below the energy required for $\beta-\mathrm{H}$ transfer from $\mathrm{C} 3$. Some of these $\mathrm{H}$-transfer steps result in stable products, e.g., $\delta$ - $\mathrm{H}$ transfer from $\mathrm{C} 5$, followed by water loss, yields a five-membered cyclic ketone at a final energy of 8.83, 8.97, and 9.10 eV (B3LYP, $\omega B 97 X-D$, M06-2X values, respectively). Because these isomerization reactions likely take place over tight transition states, they are more energetically and kinetically hindered than the already suppressed McLafferty rearrangement or $\beta-\mathrm{H}$ transfer. Therefore, these processes can be ruled out notwithstanding the stability of some of their final products.

The activation energy drops precipitously to $1.3 \mathrm{eV}$ (B3LYP/6-31G(d) electronic energy) for transferring the allylic hydrogen from $\mathrm{C} 8$ to the hydroxyl group, driven by the resonance stabilization of the transition state by the neighboring double bond (Scheme 1). The transition state energies have been evaluated using the full basis sets and the B3LYP, $\omega B$ 97X-D, M06-2X functionals as $9.12,8.99$, and $9.45 \mathrm{eV}$, making this by far the most energetically appealing isomerization route, which eventually leads to water loss and an 8-membered cyclic ketone at 8.86, 8.95, and $9.44 \mathrm{eV}$, respectively. The enolic tautomers of these cyclic ketone cations are about $0.5 \mathrm{eV}$ more stable, making the overall water loss from the oleic acid cation to form the cyclic enol almost isoenergetic. However, higher H-transfer barriers make enol formation unlikely close to the water-loss threshold. The presence of allylic hydrogen atoms in unsaturated carboxylic acids thus explains why their loss by dehydration arises as a major dissociative photoionization process surpassing the McLafferty rearrangement. In addition to the former process entailing a rather low barrier, the latter one is inhibited by the only partial positive charge at the carboxyl group. The hydrogens bound to the $s p^{2}$ carbons are also quite acidic, but 
water elimination can only take place over energetic and tight transition states, which is why we assume these $\mathrm{H}$ atoms to be immobile. On the other hand, the activation of the allylic hydrogens on the far side of the double bond, at C11, yielding a 11-membered cyclic ketone after water elimination, may take place at similar activation energies yielding products of comparable energy as at C8 within $100 \mathrm{meV}$. Therefore, both C8 and C11 allylic hydrogens may be attacked by the carboxylic group, and are responsible for the water loss dissociative photoionization process. These reaction paths also explain the general suppression of the McLafferty rearrangement and the rise of the water loss peak in the fragmentation of unsaturated carboxylic acids in general, as discussed in the context of their electron ionization mass spectra.

At higher energies, numerous fragment ions rise simultaneously, which suggests that several dissociation coordinates become energetically and kinetically allowed at a quasidegenerate threshold. The almost simultaneous opening up of multiple H-transfer channels may lead to stable leaving groups, which possibly yield fragment ions in exothermic processes with more internal energy than the precursor. ${ }^{[35]}$ In such cases, sequential dissociation reactions can take place without the intermediate ever being detectable, ${ }^{[56]}$ which may render the dissociation mechanism intractable in large molecules. However, the low-mass fragments in the electron ionization mass spectrum of oleic acid and trans-7- and trans-9-octadecene, as listed in the NIST Chemistry Webbook, ${ }^{[34]}$ are remarkably similar, which suggests that a dominant high-energy dissociation channel is the sequential fragmentation process of the carbon chain after the oxygen content is eliminated from the parent ion. High resolution energy dependent mass spectra would be required to understand the oxygen elimination process in the intermediate energy range, which are not available.

We have used unscaled B3LYP harmonic vibrational frequencies and rotational constants to calculate the thermal energy distribution of oleic acid Figure 6(f). The rate constants for the rate determining step in water loss, i.e., H-transfer, are based on the cation density of states and the transition state number of states. The time-of-flight distributions were modeled to obtain experimental unimolecular dissociation rate constants based on the asymmetry of the water-loss peak. The width of the breakdown diagram is determined predominantly by the internal energy distribution of the sample. Despite the moderate thermodesorber temperature of $130{ }^{\circ} \mathrm{C}$, the experimental data are indicative of an internal temperature of about $200{ }^{\circ} \mathrm{C}$. Although generally no cooling effects are expected in thermodesorber experiments, ${ }^{[63]}$ increased model temperatures 
are still counter-intuitive considering that both collisional and evaporative cooling effects may be at play. ${ }^{[64]}$ We propose three possible reasons for this discrepancy: (i) the tip temperature may be somewhat higher than measured, (ii) applying the harmonic oscillator approximation in internal energy distribution calculations of the large oleic acid molecule at moderate temperatures may be fraught with uncertainty, similar to its application to small molecules at high temperatures, ${ }^{[65]}$ as also evident from the calculated internal energy distribution in Figure 6(f), which predicts barely any neutrals with less than $1 \mathrm{eV}$ internal energy, and (iii) inelastic impact of the oleic acid particles on the heated surface may also enhance heating by ca. $10 \mathrm{~K}$. The transition state frequencies were varied in the statistical model to reproduce the measured rates and breakdown curves. ${ }^{[53]}$ The model yielded a $0 \mathrm{~K}$ appearance energy of $9.77 \mathrm{eV}$, neglecting tunneling effects (cf. the average DFT activation energy of $9.19 \mathrm{eV}$ ). The model breakdown diagram and TOF distributions can be compared with the experimental data in Figures 5 and 6. Figure 6 also shows the fitted rate curve underlying the statistical model to reproduce the experimentally measured rates in the kinetic window and the internal energy distribution of neutral oleic acid. It is also interesting to compare the ionization, activation and reaction energies calculated using different functionals and basis sets. In the B3LYP/6-311++G(d,p), $\omega B$ 97X-D/def2-TZVP and M062X/def2-TZVP series, B3LYP energies were consistently lower than, $\omega$ B97X-D energies about equal to and M06-2X energies higher than their average by $-0.19,-0.01$, and $0.20 \mathrm{eV}$, respectively. Because of the better agreement of the calculated activation energy and the modelled threshold (9.44 vs. $9.77 \mathrm{eV}$ ) as well as between the calculated adiabatic ionization energy and the photoionization onset ( $8.44 \mathrm{vs} .8 .51 \mathrm{eV})$ it is tempting to assume that the M06-2X functional delivered superior energetics compared with the other functionals used.

When discussing the influence of a substituent on the chemistry of a more or less distant site in a molecule, through-bond and through-space contributions are typically distinguished. ${ }^{[66]}$ However, in floppy systems containing long and flexible carbon chains, a distant site, such as the $\mathrm{C}=\mathrm{C}$ double bond about $10 \AA$ from the carboxylic group in $\mathrm{C} 18$ at the minimum geometry, may become the active site by charge delocalization, low energy conformational change and, as is the case in the low-energy fragmentation of oleic acid cations, can dominate the unimolecular reaction chemistry of a species. 


\section{Conclusions}

Oleic acid aerosol particles were evaporated using a newly built thermodesorber in the immediate vicinity of the ionizing VUV beam and the threshold photoionization of oleic acid studied using imaging photoelectron photoion coincidence. The threshold photoelectron spectrum was recorded up to the onset of the second band and agrees with literature data. At the ionization onset, the parent ion is stable at $m / z=282$ in the threshold photoionization mass spectrum. At higher energies, starting at a photon energy of $9 \mathrm{eV}$, a single dominant water loss channel could be observed in internal energy selected oleic acid cations at $\mathrm{m} / \mathrm{z}=264$, followed by the appearance of numerous lighter fragment ions. Water loss was found to be the only dominant high-mass fragment ion, and previous observations of $\mathrm{m} / \mathrm{z}=280$ and $\mathrm{m} / \mathrm{z}=256$ were therefore probably due to linoleic and palmitic acid impurities, respectively, rather than dissociative photoionization of oleic acid.

Based on their electron ionization mass spectra, saturated monocarboxylic acid cations fragment by McLafferty rearrangement, of which the product ion was not observed as a major peak in the mass spectrum of oleic acid. Instead, it is dominated by the water-loss peak in this unsaturated species, similar to the mass spectrum of the dicarboxylic adipic acid, in which the first H-transfer step of the McLafferty rearrangement is followed by dehydration. However, because of the missing sequential CO loss product at $m / z=236$ in oleic acid, water loss must take place by a different mechanism here. Based on ab initio calculations, the positive charge is split between the carboxyl group and the double bond, which inhibits $\gamma$-hydrogen transfer, but promotes the transfer of the remote allylic hydrogens to the carboxyl group. After the release of $\mathrm{H}_{2} \mathrm{O}$, the fragment ion is a cyclic ketone, which is unlikely to fragment by CO loss. This also explains the suppression of the McLafferty rearrangement generally observed in the mass spectra of unsaturated monocarboxylic acids.

\section{Acknowledgement}

We are grateful to Rudolf Thermer and Lukas Oberer for developing the aerosol thermodesorber for the iPEPICO experiment. The computations took more than 2 years of CPU time on the merlin cluster at the Paul Scherrer Institute, for which we are also thankful. This research received funding from the European Community's Seventh Framework Program 
(FP7/2007-2013) under grant agreement n. ${ }^{\circ} 290605$ (COFUND: PSI-FELLOW), the Swiss Federal Office for Energy (BFE Contract Numbers SI/501269-01), and the Swiss National Science Foundation (grant 200020-172472 as well as starting grant BSSGI0_155846). 


\section{Figures}
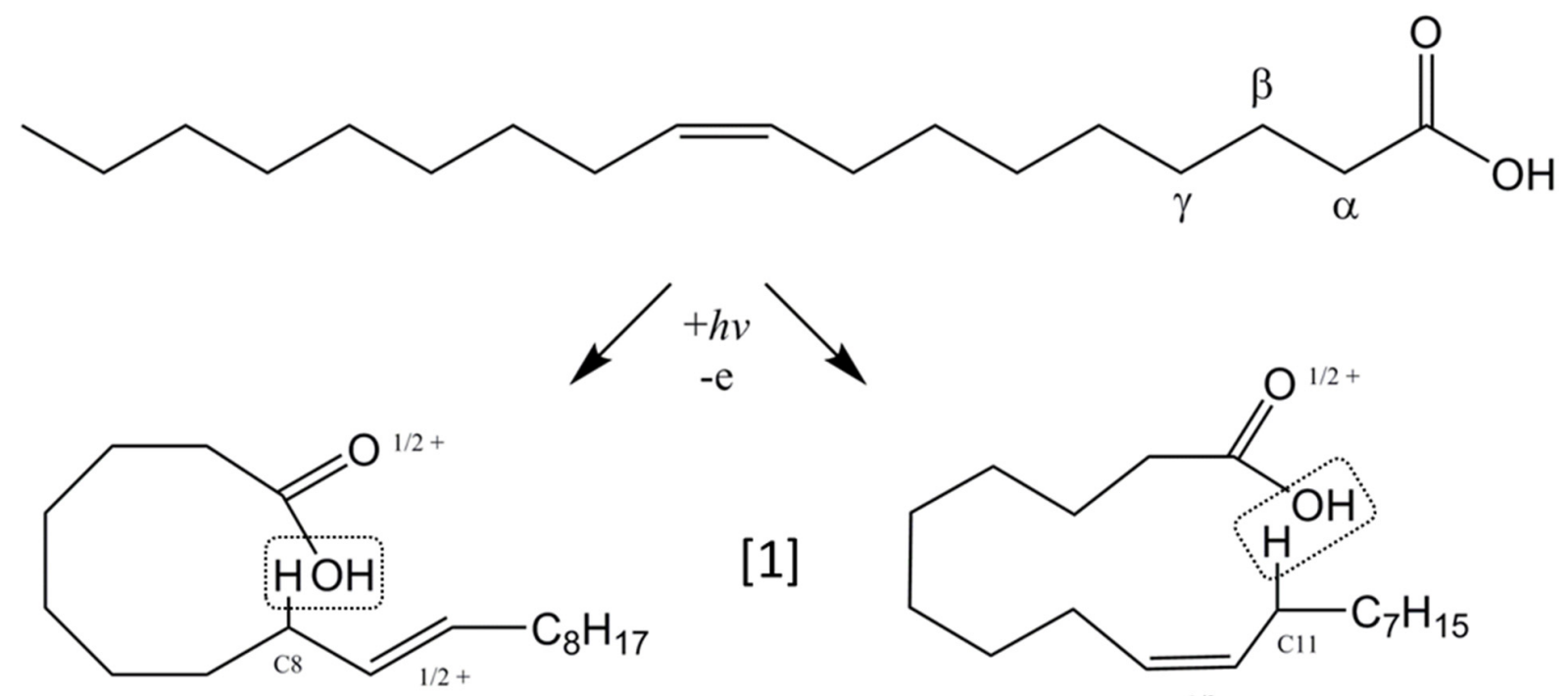

[1]

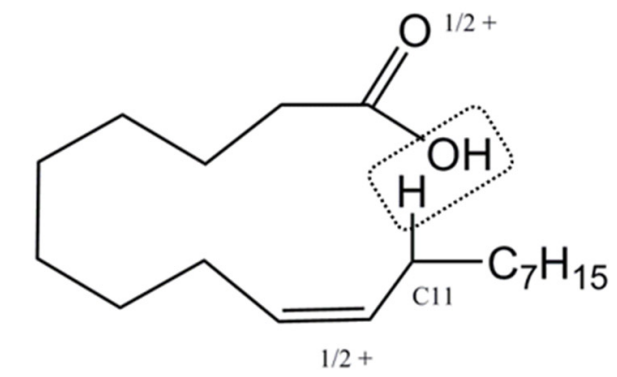

$$
\downarrow-\mathrm{H}_{2} \mathrm{O}
$$

-e

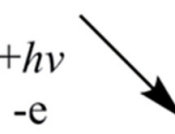

$$
\downarrow-\mathrm{H}_{2} \mathrm{O}
$$

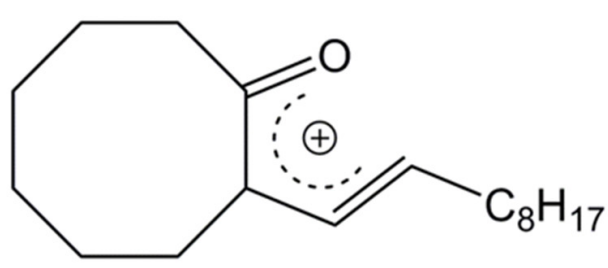

[2]

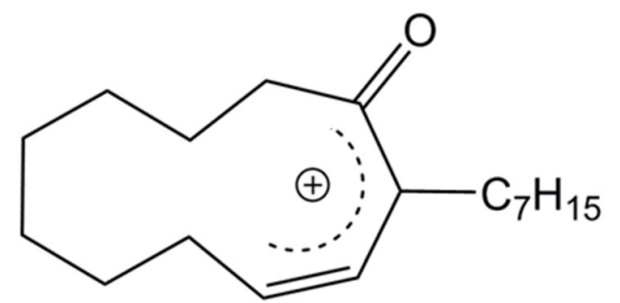

Scheme 1. The dominant low-energy dissociative photoionization pathway of oleic acid is the loss of water. H-transfer from the vicinity of the carboxyl group, i.e., from the $\beta$-, or $\gamma$-carbon, is entropically favored, but, as discussed in the text, entails larger barriers compared with the $\mathrm{OH}$ group attacking one of the allylic hydrogen atoms. Thus, dehydration yields an unsaturated cyclic ketone cation instead. 
(a)

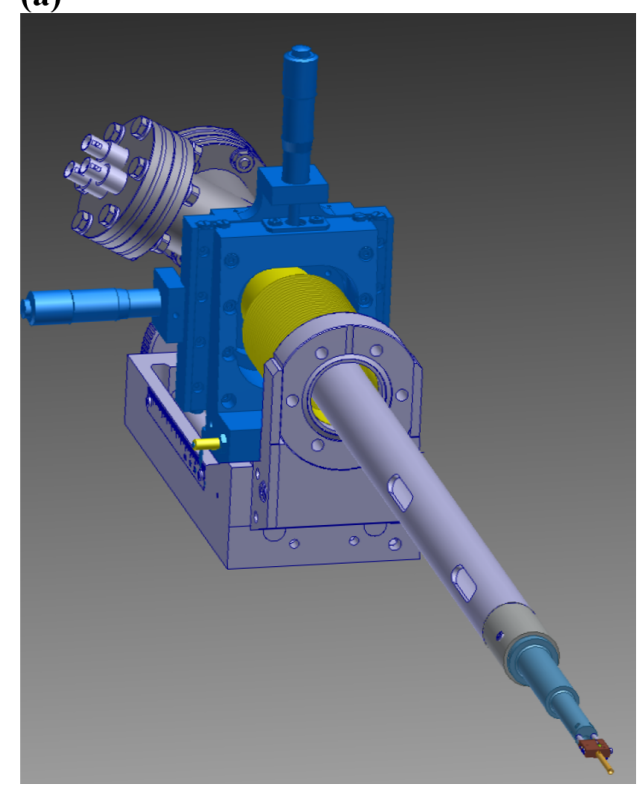

(b)

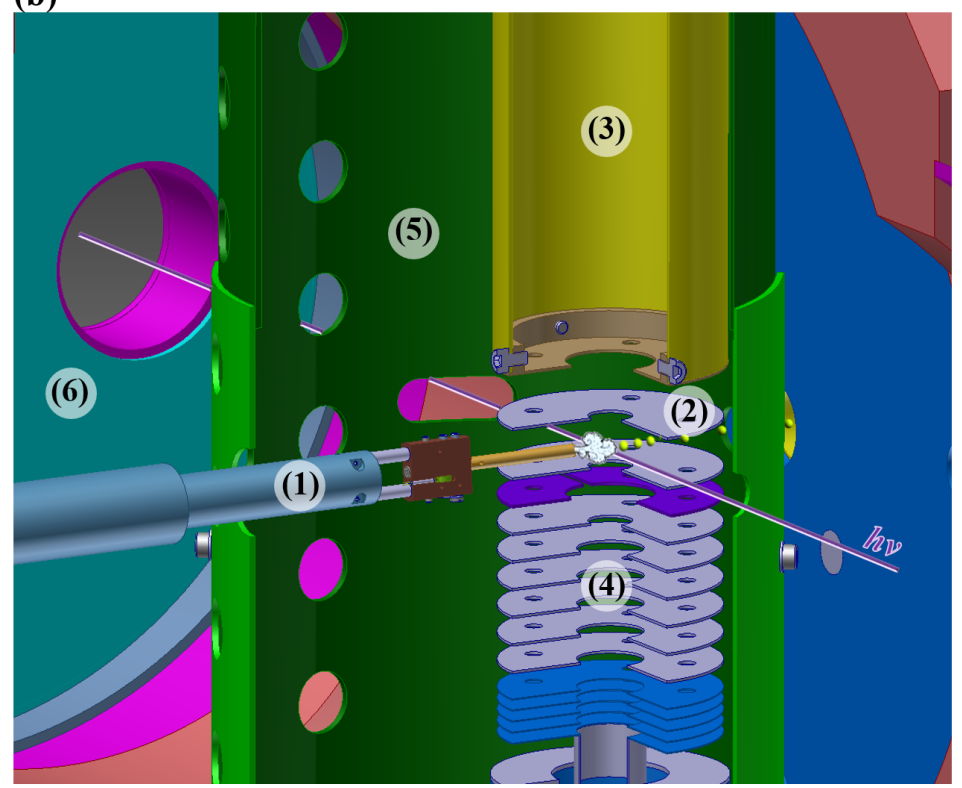

Figure 1. The aerosol thermodesorber is shown in (a) and together with the iPEPICO experimental setup in (b). The (1) thermodesorber with the resistively heated copper tip and the Pt-100 temperature sensor is inserted between the (2) extraction electrodes of the experiment. The collimated particle beam impinges on the hot surface and the particles are evaporated. Isolated sample molecules are then photoionized by monochromatic synchrotron VUV radiation. The (3) electron flight tube, (4) ion optics, (5) magnetic shield and (6) vacuum chamber are also shown. 


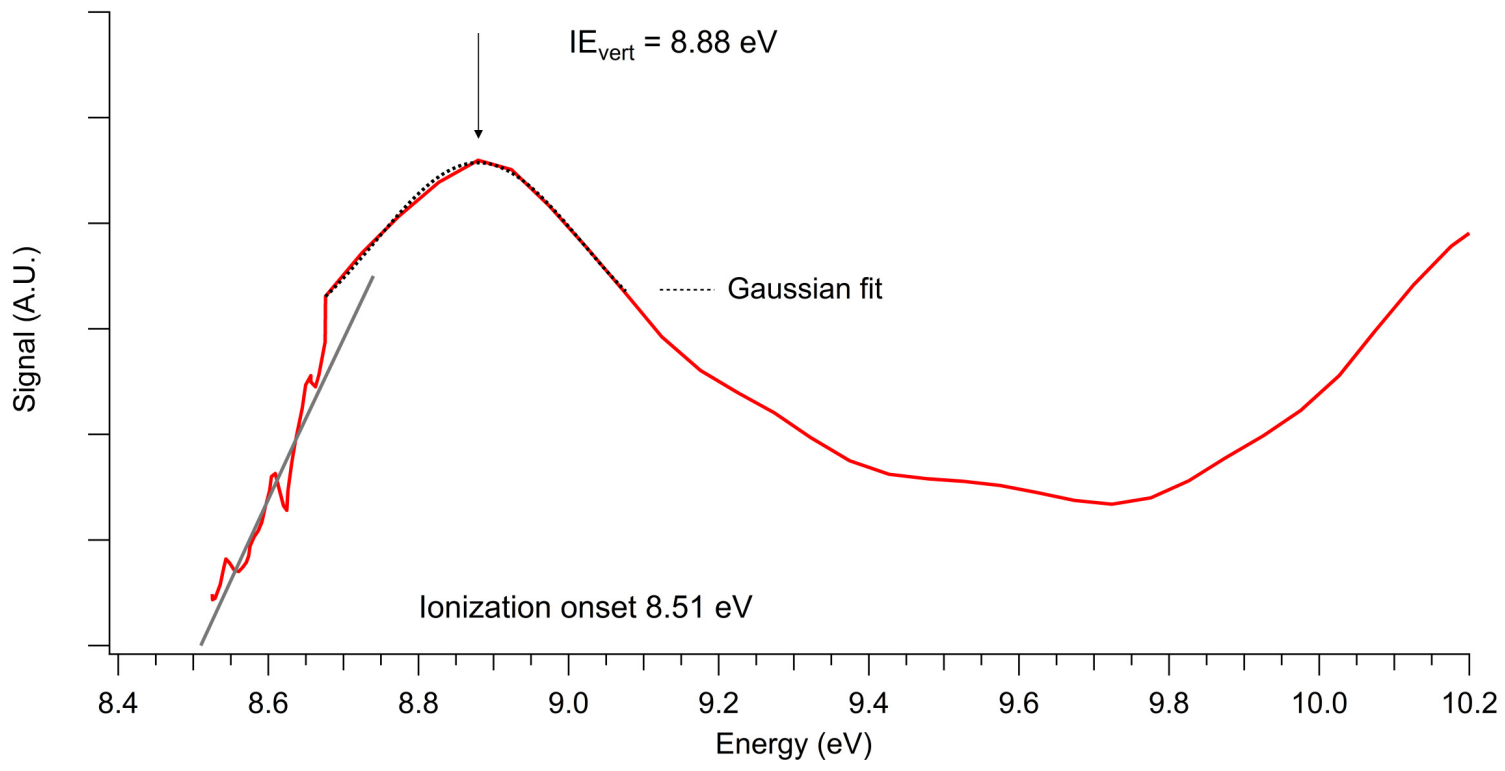

Figure 2. Threshold photoelectron spectrum of oleic acid up to $10.2 \mathrm{eV}$ photon energy. 
(a)

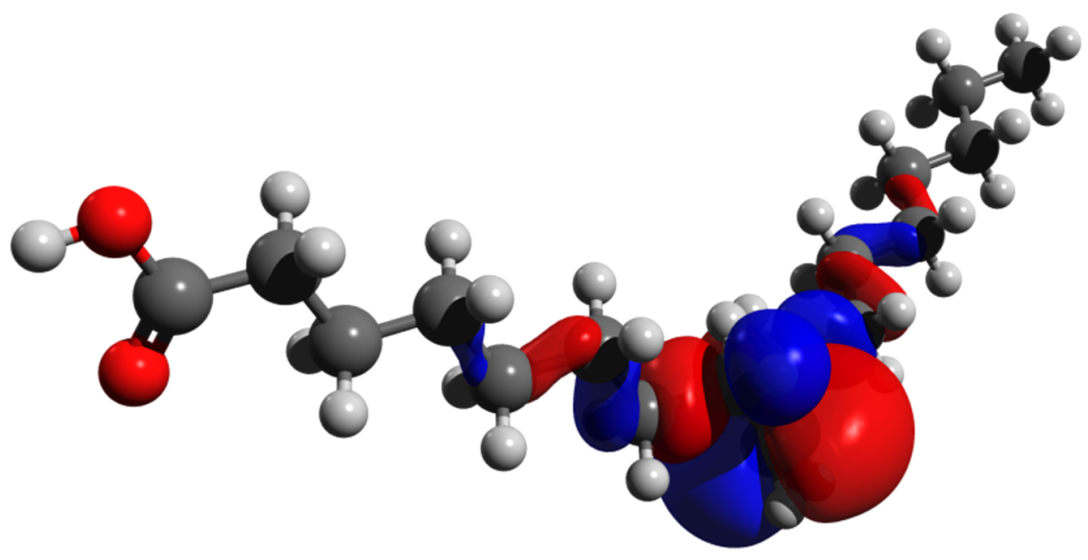

(b)

(c)
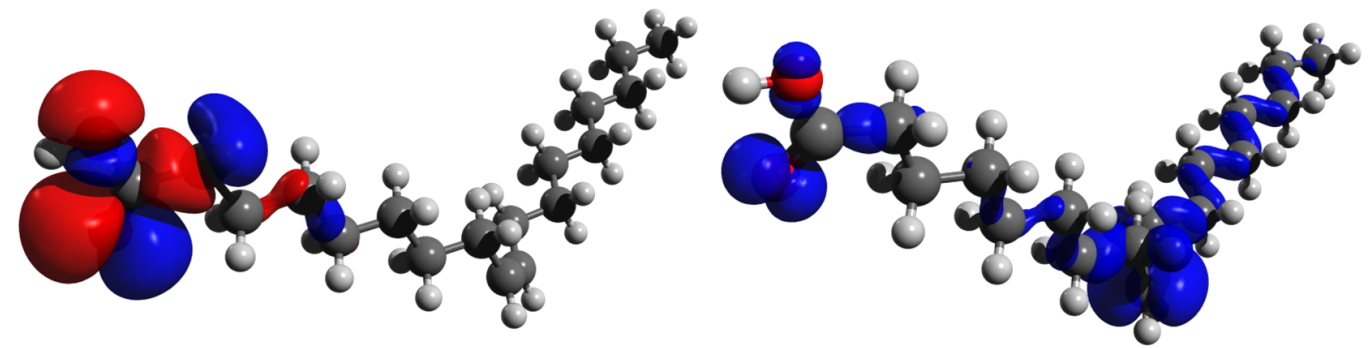

(d)

(e)
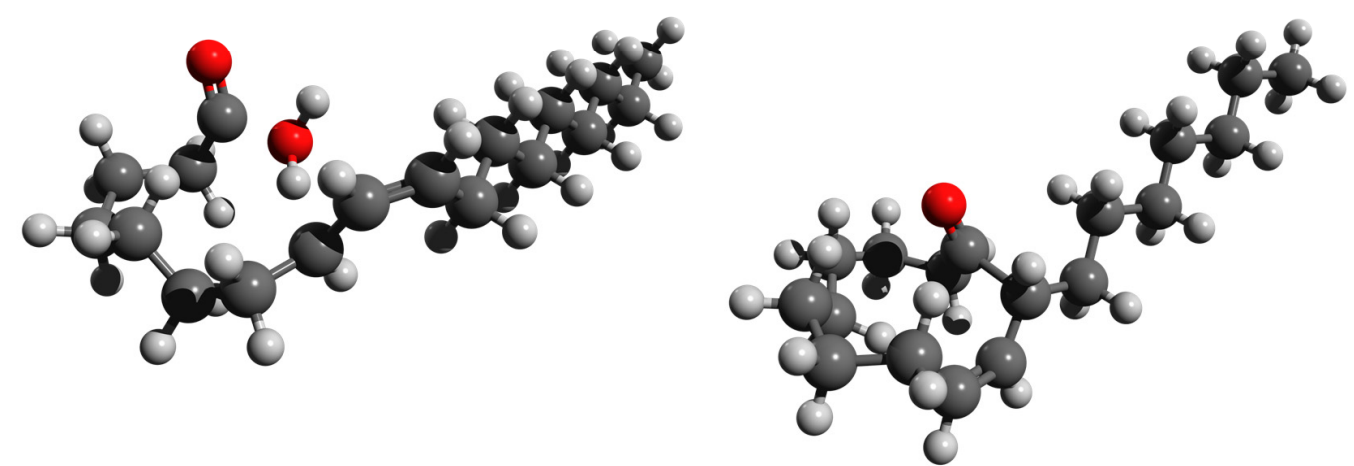

Figure 3. The B3LYP/6-311++G(d,p) HOMO of the neutral oleic acid molecule, of predominantly $\mathrm{C}=\mathrm{C}$ $\pi$ bonding character, is shown in (a). The spin density of the cation, shown in (c), suggests a significant contribution of the HOMO-1 orbital (b), of $\mathrm{C}=\mathrm{O}$ lone pair character, upon ionization. When one of the nearer allylic hydrogens is attacked by the $\mathrm{OH}$ group over the transition state shown in (d), water is lost, and the cyclic ketone in (e) is formed. 


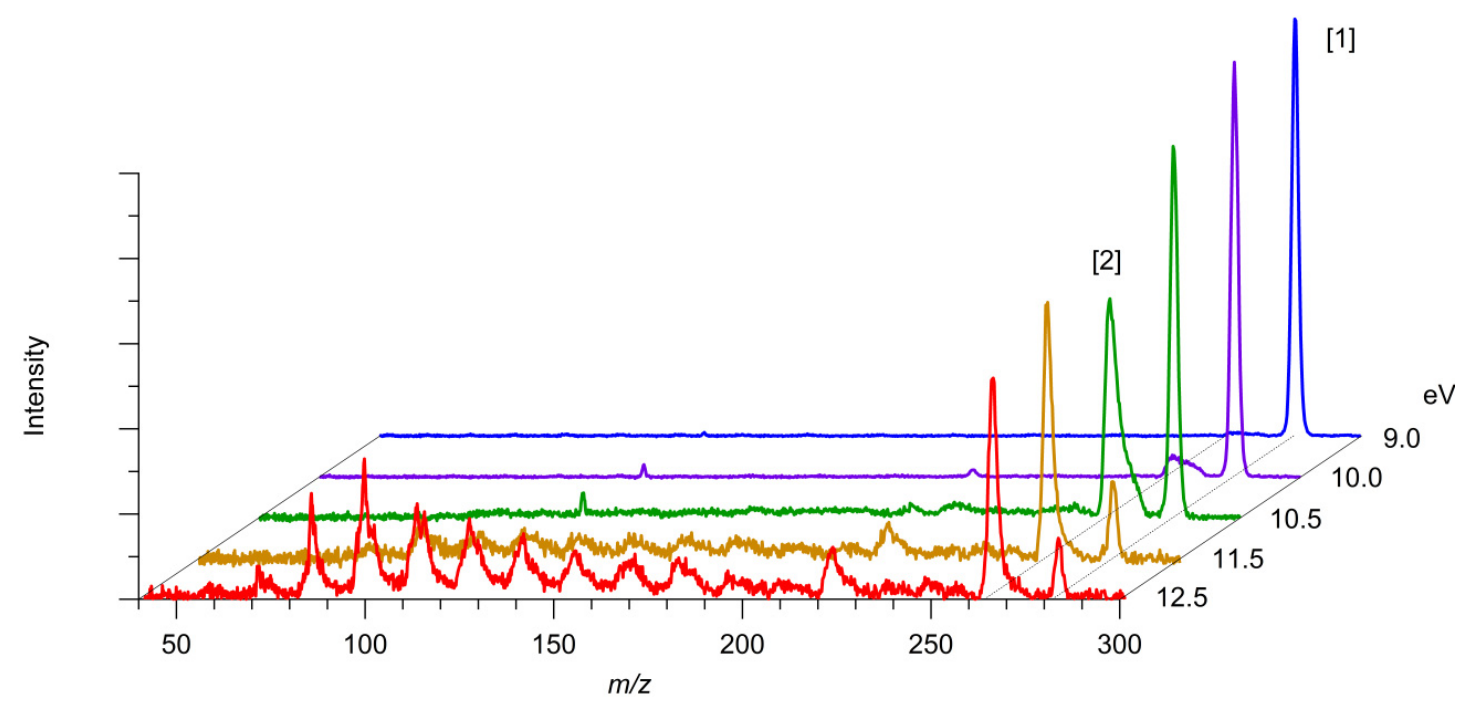

Figure 4. Illustrative photoionization mass spectra of oleic acid recorded at five photon energies. All detected electrons are accepted as TOF start signals to improve the signal-to-noise ratio. 
(a)

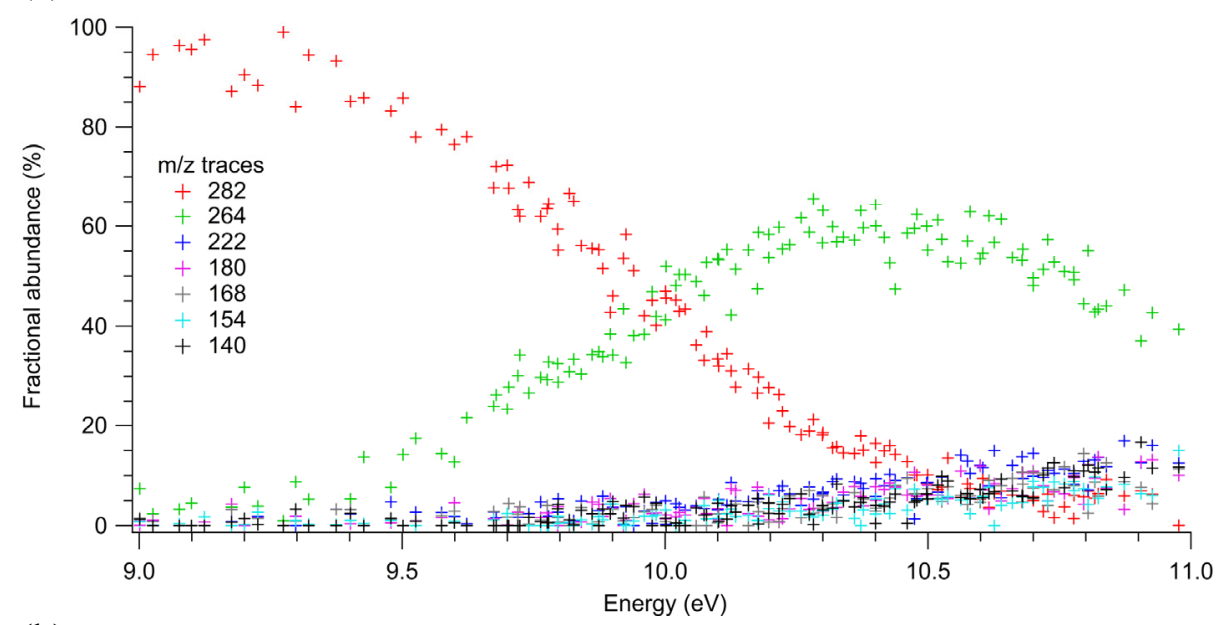

(b)

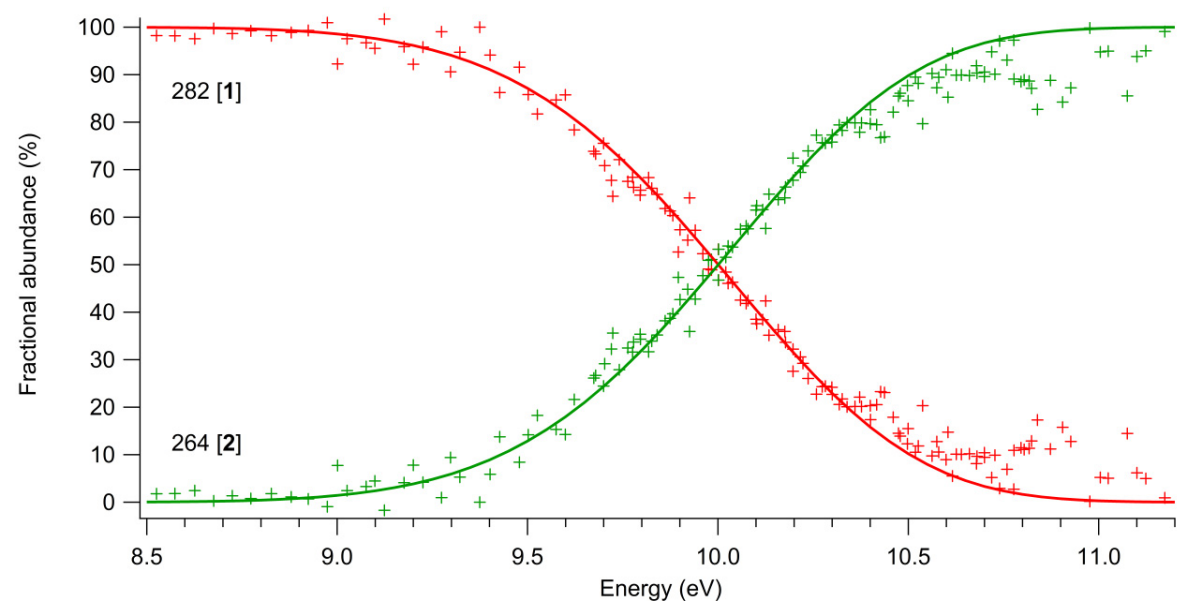

Figure 5. Parent and fragment ions down to $\mathrm{m} / \mathrm{z}=140$ are plotted in the oleic acid breakdown diagram in (a). Only the water-loss channel is plotted together with the statistical model results in (b). In both cases, threshold photoionization events are discriminated for, i.e., zero kinetic energy electrons are accepted as TOF start signal. Markers show the experimental fractional ion abundances, and solid lines show the model results. The fitted $0 \mathrm{~K}$ appearance energy of the water-loss fragment ion is $E_{0}\left([2], \mathrm{C}_{18} \mathrm{H}_{32} \mathrm{O}^{+}\right)=$ $9.77 \mathrm{eV}$. 
[1]
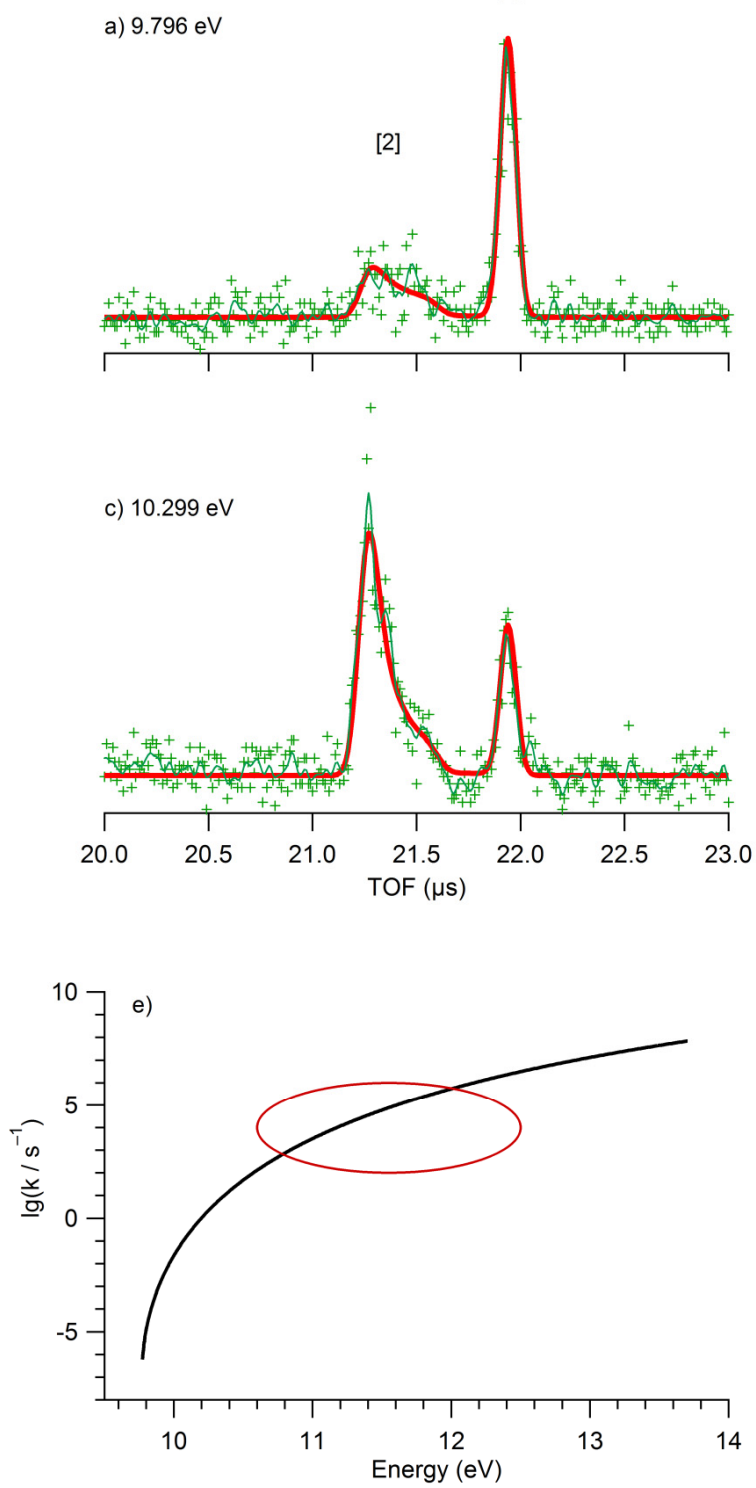

b) $10.038 \mathrm{eV}$

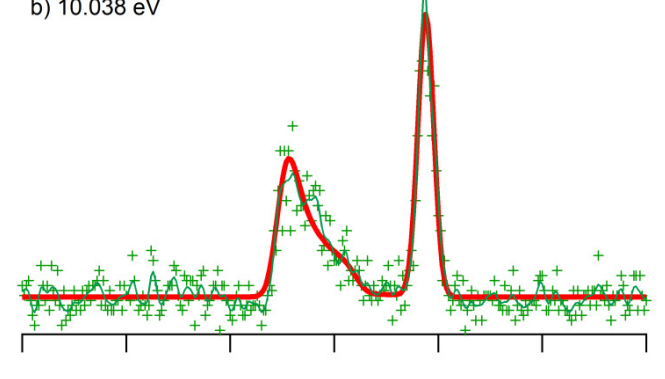

d) $10.873 \mathrm{eV}$
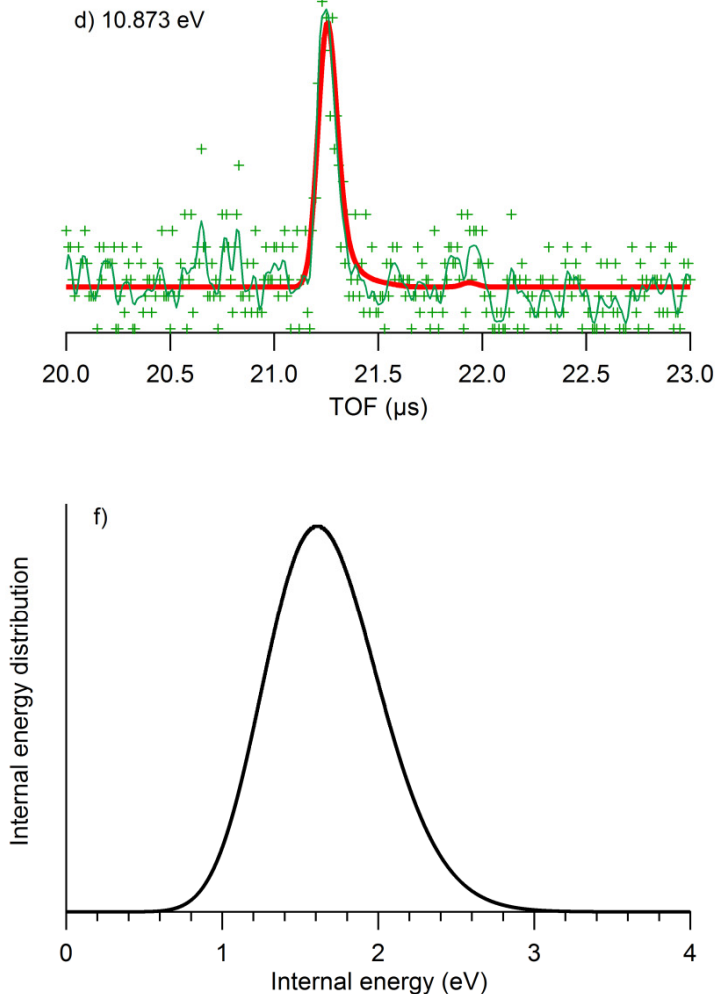

Figure 6. Modeling of the threshold ionization time-of-flight mass spectra of the oleic acid parent ion [1] and the $\mathrm{M}-\mathrm{H}_{2} \mathrm{O}$ fragment [2] at four different energies. The experimental data points $(+)$ and a binomial smoothed curve are shown in green, the model distributions are shown in red. The fitted rate curve is shown in (e) as a function of the internal energy of the oleic acid parent ion relative to the neutral ground state together with the experimental kinetic window in which experimental rate information is available. The internal energy distribution of neutral oleic acid at the model temperature is shown in (f). 


\section{References}

[1] B. Noziere, M. Kaberer, M. Claeys, J. Allan, B. D'Anna, S. Decesari, E. Finessi, M. Glasius, I. Grgic, J. F. Hamilton, T. Hoffmann, Y. Iinuma, M. Jaoui, A. Kahno, C. J. Kampf, I. Kourtchev, W. Maenhaut, N. Marsden, S. Saarikoski, J. Schnelle-Kreis, J. D. Surratt, S. Szidat, R. Szmigielski, A. Wisthaler, Chem. Rev. 2015, 115, 3919-3983.

[2] M. L. Bell, D. L. Davis, Environ. Health Persp. 2001, 109, 389-394.

[3] C. A. Pope, R. T. Burnett, M. J. Thun, E. E. Calle, D. Krewski, K. Ito, G. D. Thurston, J. Am. Med. Assoc. 2002, 287, 1132-1141.

[4] J. H. Seinfeld, S. N. Pandis, Atmospheric Chemistry and Physics: From Air Pollution to Climate Change, John Wiley and Sons, Inc, Hoboken, New Jersey, 2006.

[5] Q. Zhang, J. L. Jimenez, M. R. Canagaratna, J. D. Allan, H. Coe, I. Ulbrich, M. R. Alfarra, A. Takami, A. M. Middlebrook, Y. L. Sun, K. Dzepina, E. Dunlea, K. Docherty, P. F. DeCarlo, D. Salcedo, T. Onasch, J. T. Jayne, T. Miyoshi, A. Shimono, S. Hatakeyama, N. Takegawa, Y. Kondo, J. Schneider, F. Drewnick, S. Borrmann, S. Weimer, K. Demerjian, P. Williams, K. Bower, R. Bahreini, L. Cottrell, R. J. Griffin, J. Rautiainen, J. Y. Sun, Y. M. Zhang, D. R. Worsnop, Geophys. Res. Lett. 2007, 34, L13801.

[6] S. Fuzzi, M. O. Andreae, B. J. Huebert, M. Kulmala, T. C. Bond, M. Boy, S. J. Doherty, A. Guenther, M. Kanakidou, K. Kawamura, V. M. Kerminen, U. Lohmann, L. M. Russell, U. Poschl, Atmos. Chem. Phys. 2006, 6, 2017-2038.

[7] J. J. Schauer, G. R. Cass, Environ. Sci. Technol. 2000, 34, 1821-1832.

[8] A. L. Robinson, R. Subramanian, N. M. Donahue, A. Bernardo-Bricker, W. F. Rogge, Environ. Sci. Technol. 2006, 40, 7820-7827.

[9] J. D. Allan, P. I. Williams, W. T. Morgan, C. L. Martin, M. J. Flynn, J. Lee, E. Nemitz, G. J. Phillips, M. W. Gallagher, H. Coe, Atmos. Chem. Phys. 2010, 10, 647-668.

[10] C. Mohr, P. F. DeCarlo, M. F. Heringa, R. Chirico, J. G. Slowik, R. Richter, C. Reche, A. Alastuey, X. Querol, R. Seco, J. Peñuelas, J. L. Jimenez, M. Crippa, R. Zimmermann, U. Baltensperger, A. S. H. Prevot, Atmos. Chem. Phys. 2012, 12, 1649-1665.

[11] M. Crippa, P. F. DeCarlo, J. G. Slowik, C. Mohr, M. F. Heringa, R. Chirico, L. Poulain, F. Freutel, J. Sciare, J. Cozic, C. F. Di Marco, M. Elsasser, J. B. Nicolas, N. Marchand, E. Abidi, A. Wiedensohler, F. Drewnick, J. Schneider, S. Borrmann, E. Nemitz, R. Zimmermann, J. L. Jaffrezo, A. S. H. Prevot, U. Baltensperger, Atmos. Chem. Phys. 2013, 13, 961-981.

[12] J. D. Allan, J. L. Jimenez, P. I. Williams, M. R. Alfarra, K. N. Bower, J. T. Jayne, H. Coe, D. R. Worsnop, J. Geophys. Res-Atmos. 2003, 108, 4090.

[13] P. F. DeCarlo, I. M. Ulbrich, J. Crounse, B. de Foy, E. J. Dunlea, A. C. Aiken, D. Knapp, A. J. Weinheimer, T. Campos, P. O. Wennberg, J. L. Jimenez, Atmos. Chem. Phys. 2010, 10, 5257-5280.

[14] M. R. Alfarra, A. S. H. Prevot, S. Szidat, J. Sandradewi, S. Weimer, V. A. Lanz, D. Schreiber, M. Mohr, U. Baltensperger, Environ. Sci. Technol. 2007, 41, 5770-5777.

[15] M. F. Heringa, P. F. DeCarlo, R. Chirico, T. Tritscher, M. Clairotte, C. Mohr, M. Crippa, J. G. Slowik, L. Pfaffenberger, J. Dommen, E. Weingartner, A. S. H. Prevot, U. Baltensperger, Atmos. Chem. Phys. 2012, 12, 2189-2203.

[16] V. A. Lanz, M. R. Alfarra, U. Baltensperger, B. Buchmann, C. Hueglin, A. S. H. Prevot, Atmos. Chem. Phys. 2007, 7, 1503-1522.

[17] J. N. Shu, S. K. Gao, Y. Li, Aerosol Sci. Technol. 2008, 42, 110-113.

[18] M. A. Dreyfus, M. V. Johnston, Aerosol Sci. Technol. 2008, 42, 18-27.

[19] X. Shu, B. Yang, J. W. Meng, Y. F. Wang, J. N. Shu, Spectrosc. Lett. 2013, 46, 227-234.

[20] E. Gloaguen, E. R. Mysak, S. R. Leone, M. Ahmed, K. R. Wilson, Int. J. Mass Spectrom. 2006, 258, 74-85.

[21] E. R. Mysak, K. R. Wilson, M. Jimenez-Cruz, M. Ahmed, T. Baer, Anal. Chem. 2005, 77, 5953-5960.

[22] S. A. Skeen, H. A. Michelsen, K. R. Wilson, D. M. Popolan, A. Violi, N. Hansen, J. Aerosol Sci. 2013, 58, 86102.

[23] M. T. Baeza-Romero, F. Gaie-Levrel, A. Mahjoub, V. Lopez-Arza, G. A. Garcia, L. Nahon, Eur. Phys. J. D. 2016, 70, 154-164.

[24] M. F. Heringa, J. G. Slowik, A. S. Prevot, U. Baltensperger, P. Hemberger, A. Bodi, J. Phys. Chem. A. 2016, 120,3397-3405.

[25] T. Baer, R. P. Tuckett, Phys. Chem. Chem. Phys. 2017, 19, 9698-9723.

[26] J. J. Schauer, M. J. Kleeman, G. R. Cass, B. R. T. Simoneit, Environ. Sci. Technol. 2002, 36, 567-575. 
[27] T. D. Thornberry, J. P. D. Abbatt, Abstr. Pap. Am. Chem. S. 2002, 224, U328-U328.

[28] Y. Rudich, N. M. Donahue, T. F. Mentel, Annu. Rev. Phys. Chem. 2007, 58, 321-352.

[29] J. J. Schauer, W. F. Rogge, L. M. Hildemann, M. A. Mazurek, G. R. Cass, B. R. T. Simoneit, Atmos. Environ. 1996, 30, 3837-3855.

[30] S. Katsumata, J. Elec. Spec. Rel. Phen. 2005, 142, 265-269.

[31] D. G. Nash, X. F. Liu, E. R. Mysak, T. Baer, Int. J. Mass Spectrom. 2005, 241, 89-97.

[32] W. Z. Fang, G. Lei, X. B. Shan, F. Y. Liu, Z. Y. Wang, L. S. Sheng, J. Elec. Spec. Rel. Phen. 2011, 184, 129133.

[33] S. J. Hanna, P. Campuzano-Jost, E. A. Simpson, I. Burak, M. W. Blades, J. W. Hepburn, A. K. Bertram, Phys. Chem. Chem. Phys. 2009, 11, 7963-7975.

[34] S. E. Stein, "Mass Spectra" in NIST Chemistry WebBook, NIST Standard Reference Database Number 69. Eds. P.J. Linstrom and W.G. Mallard, National Institute of Standards and Technology, Gaithersburg MD, 20899: http://webbook.nist.gov, (retrieved 10 July 2017).

[35] X. K. Wu, X. G. Zhou, P. Hemberger, A. Bodi, J. Phys. Chem. A. 2017, 121, 2748-2759.

[36] M. Johnson, A. Bodi, L. Schulz, T. Gerber, Nucl. Instrum. Meth. A. 2009, 610, 597-603.

[37] M. Taherkhani, A. Armentano, J. Cerny, K. Muller-Dethlefs, Chem. Phys. Lett. 2016, 657, 142-147.

[38] M. Karas, D. Bachmann, F. Hillenkamp, Anal. Chem. 1985, 57, 2935-2939.

[39] P. Brechignac, G. A. Garcia, C. Falvo, C. Joblin, D. Kokkin, A. Bonnamy, P. Parneix, T. Pino, O. Pirali, G. Mulas, L. Nahon, J. Chem. Phys. 2014, 141, 164325.

[40] F. Bell, Q. N. Ruan, A. Golan, P. R. Horn, M. Ahmed, S. R. Leone, M. Head-Gordon, J. Am. Chem. Soc. 2013, $135,14229-14239$.

[41] A. Golan, K. B. Bravaya, R. Kudirka, O. Kostko, S. R. Leone, A. I. Krylov, M. Ahmed, Nat. Chem. 2012, 4, 323-329.

[42] S. Y. Liang, P. Hemberger, J. Levalois-Grutzmacher, H. Grutzmacher, S. Gaan, Chem-Eur. J. 2017, 23, 55955601.

[43] B. West, F. Useli-Bacchitta, H. Sabbah, V. Blanchet, A. Bodi, P. M. Mayer, C. Joblin, J. Phys. Chem. A. 2014, 118, 7824-7831.

[44] C. J. Koh, C. L. Liu, C. W. Harmon, D. Strasser, A. Golan, O. Kostko, S. D. Chambreau, G. L. Vaghjiani, S. R. Leone, J. Phys. Chem. A. 2011, 115, 4630-4635.

[45] F. Gaie-Levrel, G. A. Garcia, M. Schwell, L. Nahon, Phys. Chem. Chem. Phys. 2011, 13, 7024-7036.

[46] H. Dossmann, A. Schwarzenberg, D. Lesage, M. Perot-Taillandier, C. Afonso, B. C. de Miranda, G. A. Garcia, J. Phys. Chem. A. 2014, 118, 11185-11192.

[47] K. R. Wilson, M. Jimenez-Cruz, C. Nicolas, L. Belau, S. R. Leone, M. Ahmed, J. Phys. Chem. A. 2006, 110, 2106-2113.

[48] S. Amanatidis, B. L. Yoder, R. Signorell, J. Chem. Phys. 2017, 146, 224204.

[49] B. L. Yoder, A. H. C. West, B. Schlappi, E. Chasovskikh, R. Signorell, J. Chem. Phys. 2013, 138, 044202.

[50] R. Signorell, B. L. Yoder, A. H. C. West, J. J. Ferreiro, C. M. Saak, Chem. Sci. 2014, 5, 1283-1295.

[51] R. Signorell, M. Goldmann, B. L. Yoder, A. Bodi, E. Chasovskikh, L. Lang, D. Luckhaus, Chem. Phys. Lett. 2016, 658, 1-6.

[52] M. Goldmann, J. Miguel-Sanchez, A. H. C. West, B. L. Yoder, R. Signorell, J. Chem. Phys. 2015, 142, 224304.

[53] B. Sztaray, A. Bodi, T. Baer, J. Mass Spectrom. 2010, 45, 1233-1245.

[54] A. Bodi, B. Sztaray, T. Baer, M. Johnson, T. Gerber, Rev. Sci. Instrum. 2007, 78, 084102.

[55] B. Sztaray, T. Baer, Rev. Sci. Instrum. 2003, 74, 3763-3768.

[56] K. Voronova, C. M. M. Easter, K. G. Torma, A. Bodi, P. Hemberger, B. Sztaray, Phys. Chem. Chem. Phys. 2016, 18, 25161-25168.

[57] C. Y. Peng, P. Y. Ayala, H. B. Schlegel, M. J. Frisch, J. Comput. Chem. 1996, 17, 49-56.

[58] M. J. Frisch, G. W. Trucks, H. B. Schlegel, G. E. Scuseria, M. A. Robb, J. R. Cheeseman, G. Scalmani, V. Barone, B. Mennucci, G. A. Petersson, H. Nakatsuji, M. Caricato, X. Li, H. P. Hratchian, A. F. Izmaylov, J. Bloino, G. Zheng, J. L. Sonnenberg, M. Hada, M. Ehara, K. Toyota, R. Fukuda, J. Hasegawa, M. Ishida, T. Nakajima, Y. Honda, O. Kitao, H. Nakai, T. Vreven, J. A. Montgomery Jr., J. E. Peralta, F. Ogliaro, M. J. Bearpark, J. Heyd, E. N. Brothers, K. N. Kudin, V. N. Staroverov, R. Kobayashi, J. Normand, K. Raghavachari, A. P. Rendell, J. C. Burant, S. S. Iyengar, J. Tomasi, M. Cossi, N. Rega, N. J. Millam, M. Klene, J. E. Knox, J. B. Cross, V. Bakken, C. Adamo, J. Jaramillo, R. Gomperts, R. E. Stratmann, O. Yazyev, A. J. Austin, R. Cammi, C. Pomelli, J. W. Ochterski, R. L. Martin, K. Morokuma, V. G. Zakrzewski, G. A. Voth, P. Salvador, J. J. Dannenberg, S. Dapprich, A. D. Daniels, Ö. Farkas, J. B. Foresman, J. V. Ortiz, J. Cioslowski, D. J. Fox Gaussian 09, Gaussian, Inc.: Wallingford, CT, USA, 2009. 
[59] A. Bodi, T. Baer, N. K. Wells, D. Fakhoury, D. Klecyngier, J. P. Kercher, Phys. Chem. Chem. Phys. 2015, 17, 28505-28509.

[60] Z. Gengeliczki, C. I. Pongor, B. Sztaray, Organometallics. 2006, 25, 2553-2560.

[61] F. W. McLafferty, Anal. Chem. 1959, 31, 82-87.

[62] M. Winfough, K. Voronova, G. Muller, G. Laguisma, B. Sztaray, A. Bodi, G. Meloni, J. Phys. Chem. A. 2017, 121, 3401-3410.

[63] M. Tia, B. Cunha de Miranda, S. Daly, F. Gaie-Levrel, G. A. Garcia, L. Nahon, I. Powis, J. Phys. Chem. A. 2014, 118, 2765-2779.

[64] Woods, R. E. Miller, T. Baer, J. Phys. Chem. A. 2003, 107, 2119-2125.

[65] F. Holzmeier, I. Fischer, B. Kiendl, A. Krueger, A. Bodi, P. Hemberger, Phys. Chem. Chem. Phys. 2016, 18, 9240-9247.

[66] N. Sadlej-Sosnowska, J. Phys. Chem. A. 2016, 120, 6477-6484. 